\title{
Digestibilidade, Degradabilidade e Concentração Amoniacal no Rúmen de Bovinos Alimentados com Polpa Cítrica Peletizada Normal ou Queimada
}

\author{
Marco Aurélio de Felicio Porcionato', Telma Teresinha Berchielli2,3, Gumercindo Loriano \\ Franco ${ }^{4}$, Pedro de Andrade ${ }^{2}$, Roselene Nunes da Silveira ${ }^{1}$, Weber Vilas Bôas Soares ${ }^{5}$
}

RESUMO - Objetivou-se avaliar a digestibilidade e a degradabilidade de dois tipos de polpa cítrica peletizada: normal (PCPN) e queimada (PCPQ), bem como o potencial de produção de nitrogênio amoniacal com dois níveis de inclusão na ração (40 e $60 \%)$. $\mathrm{O}$ delineamento experimental utilizado foi de blocos casualizados, em esquema fatorial 2 x 2 (dois tipos de polpa e dois níveis de inclusão) e testemunha. A inclusão de polpa cítrica peletizada (PCP) nas dietas, normal ou queimada, aumentou os coeficientes de digestibilidade dos nutrientes, quando comparados com a ração testemunha, exceto para a proteína bruta (PB). Com relação aos coeficientes de digestibilidade para os dois tipos de PCP, verificou-se maior digestibilidade dos nutrientes da PCPN em relação à PCPQ, principalmente em relação a PB, FDN e FDA, pressupondo que a utilização da PCPQ pode comprometer a qualidade da ração, ocasionando perdas na produtividade dos animais. A PCPN apresentou maiores taxas de degradação da MS e FDN, quando comparada à PCPQ. Verificou-se que o potencial de degradação foi alcançado com 48 horas de incubação para MS e FDN, para todos os tratamentos. Para produção de $\mathrm{N}-\mathrm{NH}_{3}$ não foi observada diferença significativa entre os tratamentos. Contudo, a PCPQ pode ser utilizada na alimentação de bovinos, sendo sua utilização pautada na relação custo benefício.

Palavras-chave: amônia, desaparecimento, digestibilidade, polpa cítrica, ruminante, subproduto

\section{Digestibility, Degradability and Concentration of Ruminal Ammonia in Bovines Fed Diet with Citrus Pulp in Pellets}

\begin{abstract}
The objective of this research was to evaluate the digestibility and the in situ degradation of two types of citrus pulp in pellets: regular (CPPR) and burned (CPPB), as well the potential of production of $\mathrm{N}_{-} \mathrm{NH}_{3}$ in the rumen, with two levels in the diet (40 and 60\%). A randomized blocks design, in a $2 \times 2$ (two kinds of pulp and two inclusions levels) factorial and control, was used. The inclusion of citrus pulp in the diets, regular or burned, increased the coefficients of digestibility of the nutrients when compared with the control ration, except for the crude protein. A higher coefficient of digestibility of the nutrients of the regular citrus pulp was observed, when compared to the burned citrus pulp, especially in relation to crude protein, NDF and ADF. The use of burned citrus pulp can result in lower animal performance. CPPR showed higher degradation rate to DM and NDF, when compared to CPPB. DM and NDF potential degradation was obtained with $48 \mathrm{~h}$ of incubation for all treatments. No difference was oberved among treatments, concerning the $\mathrm{N}^{-\mathrm{NH}_{3}}$ production. However, CPPB could be fed to bovines and its utilization should be based on the cost benefits relation.
\end{abstract}

Key Words: ammonia, by-product, citrus pulp, digestibility, disappearance, ruminant

\section{Introdução}

Com a crescente agroindustrialização em nosso país, a produção de resíduos e subprodutos agroindustriais vem sendo cada vez maior, onde alguns destes são inaproveitáveis e poluentes, mas outros podem ser utilizados na alimentação animal como fontes alternativas de nutrientes, visando maximizar a produção animal com um baixo custo. Dentre as diversas agroindústrias, nas de processamento de citros há um subproduto comercialmente denominado de polpa cítrica peletizada (PCP), que vem recebendo destaque como fonte alternativa na alimentação de diversas categorias animais, principalmente em substituição ao milho.

A PCP é considerada um concentrado energético com características de fermentação ruminal peculiares, devido seu alto teor de carboidratos estruturais como a pectina, tornando-a um alimento muito utilizado nas rações para animais de alta exigência energética 
(Giardini, 1993). Porém, sua principal limitação nutricional é seu baixo teor de proteína bruta (PB) (Bhattacharya \& Harb, 1973). Existe ainda a polpa cítrica peletizada queimada (PCPQ), que é decorrente de um erro de processamento durante a secagem dos resíduos da laranja submetidos a altas temperaturas, ou durante o armazenamento, conferindo um aspecto torrado ao produto.

De acordo com Hentges et al. (1966), citado por Carvalho (1995), polpas mais escuras e queimadas possuem provavelmente um valor nutricional inferior, porém não se encontram na literatura trabalhos que mostrem dados a respeito deste tipo de PCP.

Em razão de o Brasil ser o maior produtor mundial de PCP, é indispensável que se aprofunde o conhecimento sobre este subproduto, para seu melhor aproveitamento na alimentação animal. Segundo os dados da Abecitrus (2002), a safra 2000/2001 foi de 14.484.000 toneladas de laranja. A PCP apresenta um equivalente de $50 \%$ do peso do fruto, fato este, que explica a grande quantidade do subproduto disponibilizado pelas agroindústrias brasileiras para o mercado.

Objetivou-se avaliar a digestibilidade, a degradabilidade e o potencial de produção de nitrogênio amoniacal das rações contendo PCPQ, em relação à polpa cítrica peletizada normal (PCPN), com dois níveis de inclusão (40 e 60\%) na ração.

\section{Material e Métodos}

O experimento foi conduzido na Faculdade de Ciências Agrárias e Veterinárias - UNESP, campus de Jaboticabal - SP. Para avaliar o potencial de produção de amônia das rações foram utilizados dez bovinos machos, cruzados $(1 / 2$ Holandesa $\times 1 / 2$ Zebu), castrados, com aproximadamente quatro anos de idade, peso vivo médio inicial de $580 \mathrm{~kg}$ e providos de cânula permanente no rúmen. No entanto, para o ensaio de degradabilidade foram utilizados apenas oito bovinos. Os animais foram mantidos em baias individuais, recebendo as rações experimentais duas vezes ao dia (7 e $13 \mathrm{~h}$ ), na quantidade de $1,2 \%$ do peso vivo.

Os alimentos utilizados nas rações foram: PCP normal (PCPN) ou queimada (PCPQ), silagem de milho, levedura, uréia e sal mineral. Após 14 dias de adaptação às rações, seguiu-se oito dias de amostragens, para cada um dos três períodos experimentais.

Após cada período, os animais foram redistribuídos, não permitindo que estes recebessem o mesmo trata- mento dos períodos anteriores. Os animais testemunha não receberam nenhum tipo de PCP. A composição bromatológica dos alimentos é está apresentada na Tabela 1.

Os tratamentos utilizados no experimento são apresentados na Tabela 2.

O delineamento experimental utilizado foi de blocos casualizados, em esquema fatorial $2 \times 2$, sendo dois tipos de PCP (normal e queimada) e dois níveis de inclusão na ração dos animais (40 e 60\%), com duas repetições para cada tratamento e os tempos de incubação como sub-parcelas.

O modelo matemático utilizado para as análises estatísticas foi o seguinte:

$$
Y_{i j k}=m+b_{k}+a_{i}+n_{j}+(a n)_{i j}+e_{i j k}
$$

em que $m=$ média geral dos tratamentos; $b_{k}=$ efeito do bloco $k(\mathrm{k}=1$ a 3$) ; a_{i}=$ efeito do tipo de polpa (normal ou queimada), $(\mathrm{i}=1$ a 2$) ; n_{j}=$ efeito do nível de inclusão na dieta (40 ou 60\%), $(\mathrm{j}=1$ a 2); (an) ${ }_{i j}=$ efeito da interação entre $a$ e $b ; e_{i j k}=$ erro experimental.

As análises estatísticas foram efetuadas no programa SAS (1990).

O ensaio da digestibilidade foi realizado através de colheita total de fezes de cada animal durante cinco dias. Após cada colheita, as fezes de cada animal foram imediatamente pesadas, homogeneizadas e retirou-se uma amostra de $10 \%$ a qual foi congelada.

Ao final de cada período, após homogeneização, colheu-se uma amostra de aproximadamente 5\% do total congelado, obtendo assim cinco amostras de cada tratamento. Essas amostras foram secas separadamente em estufa com ventilação forçada de ar, a $60^{\circ} \mathrm{C}$, por 72 horas e depois moídas, compondo uma amostra representativa dos tratamentos correspondentes a cada período, para que fossem realizadas as análises laboratoriais.

Foram determinadas: matéria seca (MS), proteína bruta $(\mathrm{PB})$, extrato etéreo (EE), fibra bruta $(\mathrm{FB})$, matéria mineral (MM) e energia bruta (EB), conforme as metodologias descritas por Silva (1990); fibra em detergente neutro (FDN), fibra em detergente ácido (FDA), proteína insolúvel em detergente neutro (PIDN), proteína insolúvel em detergente ácido (PIDA), segundo Pereira \& Rossi Júnior (1994).

O teor de carboidratos não estruturais (CNE) foi calculado por intermédio da fórmula (Hall, 1997): $C N E=100-[M M+P B+E E+(F D N-P I D N)]$. Para determinação dos nutrientes digestíveis totais 
(NDT) foi utilizada a seguinte fórmula: $N D T=E \tilde{N} N D+P B D+F B D+2,25 E E D$, em que EÑND - Extratos não nitrogenados digestíveis; PBD - Proteína bruta digestível; FBD - Fibra bruta digestível; EED - Extrato etéreo digestível.

Para os cálculos da energia digestível (ED) e da energia metabolizável (EM), utilizaram-se as seguintes fórmulas: $E D=(\% N D T / 100) \times 4,409$ e $E M=0,82 E D$, respectivamente. Para obtenção da digestibilidade da PCPN e PCPQ, utilizou-se como parâmetro a digestibilidade da ração basal: (silagem de milho, levedura, uréia e sal mineral), oferecido aos animais controle (Tabela 2), determinou-se por diferença o valor correspondente a indigestibilidade da MS e de seus nutrientes. Portanto, através da média da indigestibilidade da ração basal, foi feito por diferença o isolamento desta nos tratamentos PCPN e PCPQ, obtendo-se assim uma estimativa do quanto era excretado da ração basal e o quanto era excretado de PCP, por intermédio da seguinte fórmula matemática: Excretado PCP $(\mathrm{kg})$ = Excretado Total $(\mathrm{kg})$ (Ingestão Ração Basal (kg) $x$ \% Indigestivel Ra-

Tabela 1 - Teores médios de matéria seca (MS), proteína bruta $(\mathrm{PB})$, estrato etéreo (EE), matéria mineral $(\mathrm{MM})$, fibra em detergente neutro (FDN), fibra em detergente ácido (FDA), proteína insolúvel em detergente neutro (PIDN), proteína insolúvel em detergente ácido (PIDA), carboidratos não estruturais (CNE) e energia bruta (EB) dos alimentos (\% com base na MS)

Table 1 - Average contents of dry matter (DM), crude protein (CP), ether extract (EE), ash, neutral detergent fiber $(N D F)$, acid detergent fiber (ADF), protein insoluble in neutral detergent (PIND), protein insoluble in acid detergent (PINA), non structural carbohydrates (NEC) and crude energy (CE) of feeds (\% as DM basis)

\begin{tabular}{|c|c|c|c|c|c|c|c|c|c|c|}
\hline $\begin{array}{l}\text { Alimento } \\
\text { Feedstuff }\end{array}$ & $\begin{array}{l}\text { MS } \\
D M\end{array}$ & $\begin{array}{l}\text { PB } \\
C P\end{array}$ & $\begin{array}{l}\mathrm{EE} \\
E E\end{array}$ & $\begin{array}{c}\mathrm{MM} \\
\text { Ash }\end{array}$ & $\begin{array}{r}\text { FDN } \\
N D F\end{array}$ & $\begin{array}{l}\mathrm{FDA} \\
A D F\end{array}$ & $\begin{array}{l}\text { PIDN } \\
P I N D\end{array}$ & $\begin{array}{l}\text { PIDA } \\
P I A D\end{array}$ & $\begin{array}{l}\mathrm{CNE} \\
N E C\end{array}$ & $\begin{array}{c}\mathrm{EB} \\
C E \\
\mathrm{Mcal} / \mathrm{kg}\end{array}$ \\
\hline $\begin{array}{l}\text { Silagem } \\
\text { de milho }\end{array}$ & 30,08 & 7,80 & 2,18 & 6,26 & 54,37 & 26,64 & 32,00 & 19,00 & 31,68 & 3,88 \\
\hline $\begin{array}{l}\text { Corn silage } \\
\text { Levedura } \\
\text { Yeast }\end{array}$ & 90,29 & 37,79 & 6,13 & 6,14 & - & - & - & - & 49,94 & 4,08 \\
\hline $\begin{array}{l}\text { Uréia } \\
\text { Urea }\end{array}$ & 98,00 & 277,12 & - & - & - & - & - & - & - & - \\
\hline $\begin{array}{l}{ }^{1} \mathrm{PCPN} \\
C P P R\end{array}$ & 88,55 & 7,16 & 1,14 & 5,59 & 21,05 & 22,58 & 22,00 & 6,00 & 66,62 & 3,72 \\
\hline $\begin{array}{l}{ }^{2} \mathrm{PCPQ} \\
C P P B\end{array}$ & 89,78 & 7,16 & 1,62 & 6,39 & 28,49 & 26,82 & 27,00 & 19,00 & 58,28 & 3,82 \\
\hline
\end{tabular}

${ }^{1}$ Polpa cítrica peletizada normal; ${ }^{2}$ Polpa cítrica peletizada queimada.

${ }^{1}$ Regular citrus pulp in pellets; ${ }^{2}$ Burned citrus pulp in pellets.

Tabela 2 - Participação dos ingredientes nas rações experimentais contendo diferentes níveis de PCPN e PCPQ

Table 2 - Participation of ingredients in the experimental diets with different levels of CPPR and CPPB

\begin{tabular}{|c|c|c|c|c|c|}
\hline $\begin{array}{l}\text { Ingredientes } \\
\text { Ingredient }\end{array}$ & $\begin{array}{l}\text { Silagem de milho } \\
\text { Corn silage }\end{array}$ & $\begin{array}{l}\text { Levedura } \\
\text { Yeast }\end{array}$ & $\begin{array}{l}\text { Uréia } \\
\text { Urea }\end{array}$ & $\begin{array}{c}\text { PCPN }^{1} \\
\text { Regular pulp }\end{array}$ & $\begin{array}{c}\mathrm{PCPQ}^{2} \\
\text { Burned pulp }\end{array}$ \\
\hline Controle & 92,00 & 6,50 & 1,50 & 0,00 & 0,00 \\
\hline $\begin{array}{l}\text { Control } \\
\text { PCPN } 40 \%\end{array}$ & 55,17 & 3,90 & 0,90 & 40,00 & 0,00 \\
\hline $\begin{array}{l}C P P R 40 \% \\
\text { PCPQ } 40 \% \\
C P P B 40 \%\end{array}$ & 55,17 & 3,90 & 0,90 & 0,00 & 40,00 \\
\hline $\begin{array}{l}\text { PCPN } 60 \% \\
C P P R \quad 60 \%\end{array}$ & 36,80 & 2,60 & 0,60 & 60,00 & 0,00 \\
\hline $\begin{array}{l}\text { PCPQ } 60 \% \\
C P P B \quad 60 \%\end{array}$ & 36,80 & 2,60 & 0,60 & 0,00 & 60,00 \\
\hline
\end{tabular}

${ }^{1}$ Polpa cítrica peletizada normal; 2 Polpa cítrica peletizada queimada.

${ }^{1}$ Regular citrus pulp in pellets; ${ }^{2}$ Burned citrus pulp in pellets. 
ção Basal). Com os dados obtidos pela fórmula, pôde-se avaliar a digestibilidade dos dois tipos de polpa cítrica, chegando-se aos coeficientes de digestibilidade aparente da MS e de seus nutrientes.

Foram realizadas colheitas de líquido ruminal para análise do $\mathrm{N}_{-} \mathrm{NH}_{3}$ ruminal em quatorze horários, alternados em 3 dias, sendo no primeiro dia às $7 \mathrm{~h}$ (antes da alimentação), 9; 11; 13 (após a alimentação), 17 e 21 h; no segundo às $1 ; 5 ; 11 ; 14 ; 18$ e $22 \mathrm{~h}$; e no terceiro dia, às $2 \mathrm{e} 6 \mathrm{~h}$, buscando, assim, obter uma representatividade da fermentação ruminal dentro do período de 24 horas. As análises de $\mathrm{N}_{-} \mathrm{NH}_{3}$ foram realizadas segundo a metodologia citada por Preston (1988).

Para determinar a degradabilidade da MS e FDN, foram incubadas amostras de PCPN e PCPQ no rúmen por intermédio da técnica de sacos de náilon nas dimensões de $7 \times 14 \mathrm{~cm}$ e porosidade de $50 \mathrm{~mm}$, conforme metodologia descrita por Huntington \& Givens (1995). Os sacos de náilon foram incubados no rúmen por $2 ; 4 ; 8 ; 12 ; 24 ; 48 ; 72 ; 96$ e 120 horas, colocados sempre no mesmo horário ( 8 horas), para proporcionar uma mesma condição ruminal a todos os sacos. Depois de retirados do rúmen, os sacos foram lavados manualmente em água corrente e fria até que a água resultante da lavagem se tornasse límpida. Após, foram colocados para secar em estufa de ventilação forçada a $60^{\circ} \mathrm{C}$ por 48 horas.

As frações de MS solúvel da PCPN e da PCPQ foram determinadas em água, onde sacos de náilon foram colocados em banho-maria por 1 hora, a $38^{\circ} \mathrm{C}$. Posteriormente foram lavados em água corrente da mesma forma que os incubados e submetidos à secagem em estufa de ventilação forçada a $60^{\circ} \mathrm{C}$ por 48 horas e depois pesados. A perda de peso foi considerada a fração solúvel (fração $a$ ) da polpa cítrica, segundo o modelo de Mehrez \& Ørskov (1976).

Os resíduos dos sacos de náilon, colhidos após o período de incubação, foram analisados para determinação da MS e FDN, segundo a metodologia citada por Silva (1990). As degradabilidades potenciais (DP) também foram calculadas segundo o modelo proposto por Mehrez \& Ørskov (1977): $\mathrm{DP}=\mathrm{a}+\mathrm{b}\left(1-\mathrm{e}^{-\mathrm{ct}}\right)$, em que "a" é a fração solúvel; "b", a fração insolúvel potencialmente degradável; e "c", a taxa fracional de degradação da fração "b" (\%/h). A soma das frações "a" e "b" é o material potencialmente degradável no rúmen. As degradabilidades efetivas (DE) foram calculadas considerando-se as taxas de passagens de 2 e $5 \%$, estimadas pela equação proposta por Ørskov \& McDonald (1979).
As análises estatísticas do desaparecimento da MS, bem como o da FDN, foram feitas pela comparação de médias das dietas em relação aos diferentes tempos de incubação pelo teste Tukey a $5 \%$ de probabilidade.

\section{Resultados e Discussão}

Os coeficientes de digestibilidades aparente em relação ao nível de inclusão de polpa cítrica na ração, 40 e $60 \%$, para os dois tipos PCP, são apresentados na Tabela 3.

Conforme a Tabela 3, observou-se que não houve diferença significativa entre as rações com os níveis de inclusão de PCP de 40 e $60 \%(\mathrm{P}>0,05)$ para digestibilidade aparente da MS, FDN e FDA. Porém, quando as rações contendo PCP são comparadas com o controle, a inclusão de PCP, independentemente do tipo, melhorou a digestibilidade de forma significativa $(\mathrm{P}<0,05)$ para MS, FDN, FDA e aumentou os valores dos nutrientes digestíveis totais (NDT), energia digestível (ED) e energia metabolizável(EM).

$\mathrm{Na}$ Tabela 4, são mostrados os valores da digestibilidade da MS e seus nutrientes, bem como os valores de NDT das rações em relação ao tipo de PCP utilizada.

Verificou-se que os coeficientes de digestibilidade das rações que apresentavam PCPN foram significativamente maiores para todos os nutrientes $(\mathrm{P}<0,05)$, quando comparados com as rações que apresentavam PCPQ, provavelmente devido à ocorrência de complexação dos nutrientes durante o processo de carbonização da PCPQ, confirmando as afirmações de Hentges et al. (1966) e demonstrado pela digestibilidade da $\mathrm{PB}$, que foi o único nutriente da ração controle que apresentou coeficiente de digestibilidade maior $(\mathrm{P}<0,05)$ do que nas rações com PCP, sendo que o tratamento PCPQ apresentou coeficiente de digestibilidade ainda menor $(\mathrm{P}<0,05)$ que a PCPN.

$\mathrm{Na}$ Tabela 5, são apresentados os coeficientes de digestibilidade da PCPN e da PCPQ, utilizadas no experimento.

Com observação dos resultados, pode-se concluir que a inclusão de PCP na ração, independentemente do tipo, aumentou a densidade energética destas, podendo ocorrer ganhos no desempenho animal. No entanto, quando se aumentou o nível de PCP nas rações, diminuiu-se o coeficiente de digestibilidade da PB, estando em conformidade com Bhattacharya \& Harb (1973), que reportaram a baixa digestibilidade 
da PB presente na PCP, devido ao alto teor de proteína retida na parte fibrosa de sua composição.

Obtiveram-se, por intermédio da digestibilidade das rações experimentais, os valores de digestibilidade da matéria seca e seus nutrientes, bem como os valores de NDT, ED e EM, dos dois tipos de polpa cítrica utilizados.Verificou-se maior digestibilidade da PCPN em relação a todos os nutrientes, assim como valores maiores para o NDT, ED e EM, quando comparada à $\mathrm{PCPQ}$.

Os valores obtidos para o coeficiente de digestibilidade da MS da polpa cítrica são semelhantes aos encontrados por Wainman \& Dewey (1988), que, sumarizando vários experimentos, relataram valores de digestibilidade entre 72 e $92 \%$, sendo que esta variação pode ser explicada pela heterogeneidade da polpa cítrica encontrada no mercado, sendo que a carbonização deste material é um dos principais fatores na diminuição da digestibilidade (Tabela 5). A digestibilidade da matéria seca da PCPN foi de $84,14 \%$ e da PCPQ, de apenas $71,74 \%$.

Wainman \& Dewey (1988) apontaram também valores de digestibilidade da matéria orgânica (MO) da polpa cítrica variando entre 83 e $96 \%$. Os resultados encontrados neste experimento estão coerentes com os valores acima citados para o coeficiente digestibilidade da PCPN (87,96\%), porém desviam do valor encontrado para PCPQ $(76,25 \%)$. Os resultados refletem a elevada digestibilidade da PCP, porém deve-se ter cautela ao utilizar a PCPQ, pois possui valores bem abaixo dos encontrados nas tabelas convencionais de nutrição, podendo comprometer a qualidade da ração, ocasionando diminuição no desempenho animal.

Tabela 3 - Coeficientes de digestibilidade aparente da MS, PB, FDN, FDA, CNE, PIDN e PIDA e valores médios de nutrientes digestíveis totais (NDT), energia bruta (EB), energia digestível (ED) e energia metabolizável (EM), para os níveis de inclusão (NI) de PCP 40 e 60\%, comparados ao controle

Table 3 - Apparent digestibility coefficients of DM, CP, NDF, ADF, NEC, PIND and $P I A D$ and means values of total digestible nutrients (TDN), crude energy $(C E)$, digestible energy (DE), metabolizable energy (ME), for the inclusion levels (IL) of CPP 40 and 60\%, compared to the control

\begin{tabular}{|c|c|c|c|c|}
\hline \multirow[b]{2}{*}{$\begin{array}{l}\text { Nutrientes } \\
\text { Nutrients }\end{array}$} & \multicolumn{3}{|c|}{$\begin{array}{c}\text { Tratamentos } \\
\text { Treatments }\end{array}$} & \multirow[b]{2}{*}{ CV $(\%)$} \\
\hline & $\begin{array}{l}\text { Controle } \\
\text { Control }\end{array}$ & $\begin{array}{c}\mathrm{NI}-40 \% \\
I L\end{array}$ & $\begin{array}{c}\mathrm{NI}-60 \% \\
I L\end{array}$ & \\
\hline $\begin{array}{l}\text { MS (\%) } \\
D M(\%)\end{array}$ & $60,27 b$ & $68,99 \mathrm{a}$ & $68,99 a$ & 7,19 \\
\hline $\begin{array}{l}\mathrm{PB}(\%) \\
C P(\%)\end{array}$ & $66,46 a$ & $58,23 b$ & $50,89 \mathrm{c}$ & 12,29 \\
\hline $\begin{array}{l}\mathrm{FDN}(\%) \\
N D F(\%)\end{array}$ & $43,21 b$ & $50,50 \mathrm{a}$ & $45,26 a$ & 17,16 \\
\hline $\begin{array}{l}\text { FDA }(\%) \\
A D F(\%)\end{array}$ & $36,22 b$ & $50,00 \mathrm{a}$ & $50,86 a$ & 18,10 \\
\hline $\begin{array}{l}\mathrm{CNE}(\%) \\
N E C(\%)\end{array}$ & $90,48 b$ & $94,94 a$ & $94,31 \mathrm{a}$ & 2,14 \\
\hline $\begin{array}{l}\text { PIDN (\%) } \\
\text { PIND (\%) }\end{array}$ & $73,72 \mathrm{a}$ & $66,45 b$ & $64,05 b$ & 7,40 \\
\hline $\begin{array}{l}\text { PIDA (\%) } \\
\text { PIAD (\%) }\end{array}$ & $63,46 a$ & $47,89 b$ & $43,68 b$ & 18,52 \\
\hline $\begin{array}{l}\text { NDT }(\%) \\
T D N(\%)\end{array}$ & $62,50 \mathrm{~b}$ & $69,88 \mathrm{a}$ & $70,71 \mathrm{a}$ & 7,35 \\
\hline $\begin{array}{l}\mathrm{EB}(\mathrm{Mcal} / \mathrm{kg} \mathrm{MS}) \\
C E(\text { Mcal } / \mathrm{kg} D M)\end{array}$ & $57,61 b$ & $67,61 \mathrm{a}$ & $67,05 a$ & 6,82 \\
\hline $\begin{array}{l}\mathrm{ED}(\mathrm{Mcal} / \mathrm{kg} \mathrm{MS}) \\
D E(M c a l / k g D M)\end{array}$ & $2,21 \mathrm{~b}$ & $2,57 \mathrm{a}$ & $2,55 \mathrm{a}$ & 7,31 \\
\hline $\begin{array}{l}\mathrm{EM}(\mathrm{Mcal} / \mathrm{kg} \mathrm{MS}) \\
M E(\text { Mcal/kg DM) }\end{array}$ & $1,81 b$ & $2,11 \mathrm{a}$ & $2,09 a$ & 7,29 \\
\hline
\end{tabular}

CV - coeficiente de variação (CV - coefficient of variation).

Médias seguidas pelas mesmas letras nas linhas não diferem $(P>0,05)$ pelo teste Tukey. Means followed by the same letter are not different $(P>.05)$ by Tukey test. 
Em relação à $\mathrm{PB}$, verificou-se na literatura valores de coeficiente de digestibilidade variando entre 40 e $65 \%$ (Wainman \& Dewey, 1988), estando os resultados deste experimento próximos a estes valores para a PCPN $(48,18 \%)$. Para a PCPQ o valor de digestibilidade foi de $16,70 \%$, o que indica a queda no coeficiente de digestibilidade das rações experimentais com a participação deste alimento. Isto pode ser explicado pelo processo de aquecimento sofrido pela PCPQ, tendo este alimento sido exposto à temperatura superior a $65^{\circ} \mathrm{C}$, por tempo prolongado, favorecendo a ocorrência de complexação entre os carboidratos solúveis e grupos aminas dos aminoácidos, resultando em compostos de baixa digestibilidade denominados produtos da reação de Maillard. A formação desses produtos resulta em queda na digestibilidade da proteína e aumento nos teores de proteína insolúvel em detergente ácido (PIDA), não disponível aos microrganismos do rúmen
(Van Soest, 1994).

Os valores dos coeficientes de digestibilidade obtidos para FDN e FDA confirmam o relato de alguns autores (Ben-Ghedalia et al., 1989; Fegeros et al., 1995), no que diz respeito à excelente qualidade da fibra deste material. Como apresentado na Tabela 5 , os coeficientes de digestibilidade da FDN e FDA da PCPN foram de 67,72 e 86,00\%. Porém, na PCPQ, estes valores foram bem menores, 50,49 e 46,35\% respectivamente, que pode ser explicado pela ocorrência de reação de Maillard neste tipo de polpa, como explicado anteriormente, provocando a condensação de carboidratos e proteínas na presença de água (Van Soest, 1994).

Pode-se concluir que a baixa digestibilidade da PB e dos componentes da fibra é que mais contribui para a menor digestibilidade da matéria seca e matéria orgânica da PCPQ.

O valor de NDT obtido para a PCPN $(84,25 \%)$,

Tabela 4 - Coeficientes de digestibilidade aparente da MS, PB, FDN, FDA, CNE, PIDN e PIDA e valores médios de NDT, EB, ED e EM para as rações com PCPN e PCPQ, comparadas ao controle

Table 4 - Apparent digestibility coefficients of the DM, CP, NDF, ADF, NEC, PIND and PIAD and means values of TDN, CE, DE and ME to diets with CPPR and CPPB, compared to the control

\begin{tabular}{|c|c|c|c|c|}
\hline \multirow[b]{2}{*}{$\begin{array}{l}\text { Tratamentos } \\
\text { Treatments }\end{array}$} & \multicolumn{3}{|c|}{$\begin{array}{l}\text { Nutrientes } \\
\text { Nutrients }\end{array}$} & \multirow[b]{2}{*}{$\mathrm{CV}(\%)$} \\
\hline & $\begin{array}{l}\text { Controle } \\
\text { Control }\end{array}$ & $\begin{array}{c}\text { PCPN } \\
\text { Regular pulp }\end{array}$ & $\begin{array}{c}\text { PCPQ } \\
\text { Burnned pulp }\end{array}$ & \\
\hline$\overline{\mathrm{MS}(\%)}$ & & & & \\
\hline $\begin{array}{l}D M(\%) \\
\mathrm{PB}(\%)\end{array}$ & $60,27 \mathrm{c}$ & $72,13 a$ & $65,85 b$ & 7,19 \\
\hline $\begin{array}{l}C P(\%) \\
\text { FDN }(\%)\end{array}$ & $66,46 a$ & $59,62 b$ & $49,51 \mathrm{c}$ & 12,29 \\
\hline $\begin{array}{l}N D F(\%) \\
\text { FDA }(\%)\end{array}$ & $43,21 \mathrm{c}$ & $50,17 \mathrm{a}$ & $45,59 b$ & 17,16 \\
\hline $\begin{array}{l}A D F(\%) \\
\text { CNE (\%) }\end{array}$ & $36,22 \mathrm{c}$ & $59,57 \mathrm{a}$ & $41,29 b$ & 18,10 \\
\hline $\begin{array}{l}N E C(\%) \\
\operatorname{PIDN}(\%)\end{array}$ & $90,48 c$ & $95,58 \mathrm{a}$ & $93,67 b$ & 2,14 \\
\hline $\begin{array}{l}\text { PIND (\%) } \\
\text { PIDA (\%) }\end{array}$ & $73,72 \mathrm{a}$ & $72,61 \mathrm{a}$ & $57,89 b$ & 7,40 \\
\hline $\begin{array}{l}\text { PIAD }(\%) \\
\text { NDT }(\%)\end{array}$ & $63,46 a$ & $53,40 \mathrm{~b}$ & $38,16 b$ & 18,52 \\
\hline $\begin{array}{l}T D N(\%) \\
\text { EB (Mcal/kg MS) }\end{array}$ & $62,50 \mathrm{c}$ & $72,66 a$ & $67,93 b$ & 7,35 \\
\hline $\begin{array}{l}C E(\mathrm{Mcal} / \mathrm{kg} \mathrm{DM}) \\
\mathrm{ED}(\mathrm{Mcal} / \mathrm{kg} \mathrm{MS})\end{array}$ & $57,61 \mathrm{c}$ & $70,51 \mathrm{a}$ & $64,50 \mathrm{~b}$ & 6,82 \\
\hline $\begin{array}{l}D E(\mathrm{Mcal} / \mathrm{kg} \mathrm{DM}) \\
\mathrm{EM}(\mathrm{Mcal} / \mathrm{kg} \mathrm{MS})\end{array}$ & $2,21 \mathrm{c}$ & $2,66 \mathrm{a}$ & $2,47 b$ & 7,31 \\
\hline$M E(M c a l / k g ~ D M)$ & $1,81 \mathrm{c}$ & $2,18 \mathrm{a}$ & $2,03 b$ & 7,29 \\
\hline
\end{tabular}

CV - coeficiente de variação ( $C V$ - coefficient of variation).

Médias seguidas pelas mesmas letras nas linhas não diferem $(P>0,05)$ pelo teste Tukey. Means followed by the same letter are not different $(P>.05)$ by Tukey test. 
neste experimento, foi superior ao apresentado no NRC (2001) (79,80\%). Porém em relação à ED, o valor obtido para a PCPN foi de 3,20 Mcal $/ \mathrm{kg}$ de MS, muito próximo ao descrito no NRC (2001) que é de 3,40 Mcal $/ \mathrm{kg}$ de MS, confirmando o excelente valor energético deste alimento para alimentação de bovinos. Para a PCPQ os valores foram mais baixos, sendo NDT de $71,89 \%$ e a ED igual a $2,74 \mathrm{Mcal} / \mathrm{kg}$ de MS. A inferioridade energética da PCPQ pode ser explicada devida principalmente aos menores coeficientes de digestibilidade de sua PB, FDN e FDA.

Para o desaparecimento da MS, nos diversos tempos de incubação, verificou-se que o potencial de degradação foi alcançado com 48 horas, para todos os tratamentos, conforme mostra a Figura 1.

Na Tabela 6, observam-se os valores da fração solúvel "a", da fração potencialmente degradável "b", das degradações potenciais (DP), efetivas (DE) e taxas de degradação (kd) da PCPN e da PCPQ, em relação a degradação da MS. Dessa forma, sugerese que o processo de carbonização ou armazenamento inadequado que sofreu a PCPQ pode ter causado diminuição da quantidade de nutrientes fermentáveis no rúmen, prejudicando talvez o potencial de fermentação ruminal.

Observou-se, na Tabela 6, que a PCPQ apresentou menores taxas de degradação $(\mathrm{kd})$ comparado à PCPN para MS, podendo limitar a disponibilidade de nutrientes para animais de alto potencial genético, onde a taxa de passagem é mais rápida. Observa-se, também, que o tratamento com $40 \%$ de PCPN apresentou maior taxa de degradação $(k d)$ da $\mathrm{MS}$ em relação a inclusão de $60 \%$, e também comparado aos demais tratamentos.

Supõe-se que a diferença entre os níveis de inclusão a favor do nível de substituição de $40 \%$, seja devido à maior participação de uréia e levedura nas rações, que aliadas à maior quantidade de silagem de milho, possibilitou melhor sincronia entre a energia e proteína. Já entre os tratamentos utilizando PCPQ, não foram observadas diferenças $(\mathrm{P}>0,05)$ para taxa de degradação na MS.

Na Tabela 6, também são apresentados os valores da fração potencialmente degradável "b", DP, DE e kd da PCPN e da PCPQ, em relação à degradação da FDN, a qual apresentou o mesmo comportamento da MS e provavelmente pelas mesmas razões. É importante ressaltar que não foi observada interação bloco $\mathrm{x}$ tratamento $(\mathrm{P}>0,05)$ para a MS e FDN.
Dessa forma, sugere-se que o processo de carbonização ou armazenamento inadequado que sofreu a PCPQ pode ter causado diminuição da quantidade de nutrientes fermentáveis no rúmen, prejudicando talvez o potencial de fermentação ruminal.

Entretanto, Huntington \& Givens (1995) explicam que a degradação nos primeiros horários de incubação tem grande instabilidade, devido à grande variação que existe no tempo de colonização da fibra (lag time), podendo ocorrer variações na avaliação.

Em relação à produção de amônia ruminal, não foram observadas diferenças $(\mathrm{P}>0,05)$ entre os tratamentos, bem como não houve interação bloco $\mathrm{x}$ tratamento e tratamento $\mathrm{x}$ horários de coleta $(\mathrm{P}>0,05)$. É importante ressaltar que os resultados apresentaram altos valores de coeficiente de variação, em média $57 \%$, o que é normal dentro deste tipo de ensaio

Tabela 5 - Coeficientes de digestibilidade aparente da MS, PB, FDN, FDA, CNE, PIDN e PIDA e valores médios de NDT, EB, ED e EM para PCPN e PCPQ

Table 5 - Apparent digestibility coefficients of the DM, CP, $N D F, A D F, N E C, P I N D$ and PIAD and means values of TDN, CE, DE and ME to CPPR and CPPB

\begin{tabular}{|c|c|c|}
\hline \multirow{2}{*}{$\begin{array}{l}\text { Nutrientes } \\
\text { Nutrients }\end{array}$} & \multicolumn{2}{|c|}{$\begin{array}{l}\text { Tratamentos } \\
\text { Treatments }\end{array}$} \\
\hline & $\begin{array}{c}\text { PCPN } \\
\text { Regular pulp }\end{array}$ & $\begin{array}{c}\text { PCPQ } \\
\text { Burnned pulp }\end{array}$ \\
\hline MS (\%) & $84,14 a$ & $71,74 \mathrm{~b}$ \\
\hline $\begin{array}{l}D M(\%) \\
\mathrm{PB}(\%) \\
C P(\%)\end{array}$ & $48,18 \mathrm{a}$ & $16,70 b$ \\
\hline $\begin{array}{l}\text { FDN }(\%) \\
N D F(\%)\end{array}$ & $67,72 \mathrm{a}$ & $50,49 b$ \\
\hline $\begin{array}{l}\text { FDA (\%) } \\
A D F(\%)\end{array}$ & $86,00 \mathrm{a}$ & $46,35 b$ \\
\hline $\begin{array}{l}\mathrm{CNE}(\%) \\
\operatorname{NEC}(\%)\end{array}$ & $98,08 \mathrm{a}$ & $95,65 b$ \\
\hline $\begin{array}{l}\text { PIDN (\%) } \\
\text { PIND (\%) }\end{array}$ & $71,27 \mathrm{a}$ & $40,57 b$ \\
\hline $\begin{array}{l}\text { PIDA }(\%) \\
\text { PIAD (\%) }\end{array}$ & $27,72 \mathrm{a}$ & $14,59 b$ \\
\hline $\begin{array}{l}\text { NDT }(\%) \\
T D N(\%)\end{array}$ & $84,25 a$ & $71,89 b$ \\
\hline $\begin{array}{l}\mathrm{EB}(\mathrm{Mcal} / \mathrm{kg} \mathrm{MS}) \\
C E(M c a l / k g D M)\end{array}$ & $87,96 a$ & $72,60 b$ \\
\hline $\begin{array}{l}\mathrm{ED}(\mathrm{Mcal} / \mathrm{kg} \mathrm{MS}) \\
D E(M c a l / k g D M)\end{array}$ & $3,20 \mathrm{a}$ & $2,74 \mathrm{~b}$ \\
\hline $\begin{array}{l}\mathrm{EM}(\mathrm{Mcal} / \mathrm{kg} \mathrm{MS}) \\
M E(M c a l / k g D M)\end{array}$ & $2,62 \mathrm{a}$ & $2,25 b$ \\
\hline
\end{tabular}

Médias seguidas pelas mesmas letras nas linhas não diferem $(P>0,05)$ pelo teste Tukey.

Means followed by the same letter are not different $(P>.05)$ by Tukey test. 
onde são avaliados parâmetros ruminais. Fato semelhante foi observado por Wallace (1995), que, trabalhando com animais isogênicos alimentados com a mesma ração e no mesmo ambiente, encontrou diferenças nos produtos da fermentação destes animais, indicando que, para estas variáveis com alto coeficiente de variação, deve-se isolar o efeito do animal.

Sobre a possível influência do $\mathrm{N}^{-\mathrm{NH}_{3}}$ ruminal sobre a fermentação microbiana, os dados médios encontrados $(19,43 \mathrm{mg} / \mathrm{dL})$ encontram-se acima dos
$5 \mathrm{mg} / \mathrm{dL}$ recomendados por Satter \& Roffler (1979) como o mínimo necessário para que haja fermentação ruminal e abaixo daqueles encontrados por Mehrez \& Ørskov (1976), que recomendam $23 \mathrm{mg} / \mathrm{dL}$ para que os microorganismos potencializem a fermentação microbiana. Não foram observadas diferenças $(\mathrm{P}>0,05)$ entre tratamentos. Todavia, observaram-se diferenças $(\mathrm{P}<0,05)$ entre os horários de coleta, como mostra a Figura 2.

Foram observados valores diferentes de $\mathrm{NH}_{3}$

Tabela 6 - Fração solúvel (a), fração insolúvel, mas potencialmente degradável (b), taxa de passagem (kp), degradação efetiva (DE), degradação potencial (DP) e taxa de degradação (kd) da MS e da FDN das rações com diferentes níveis de PCPN e PCPQ

Table 6 - Soluble (a), potentially degradable fractions (b), passage rate (kp), effective degradability (DE), potential degradability $(D P)$ and degradation rate $(k d)$ of DM and NDF of diets with different levels of $C P P R$ and $C P P B$

\begin{tabular}{|c|c|c|c|c|c|c|c|c|}
\hline & \multicolumn{4}{|c|}{$\begin{array}{c}\text { PCPN } \\
\text { Regular pulp }\end{array}$} & \multicolumn{4}{|c|}{$\begin{array}{c}\text { PCPQ } \\
\text { Burnned pulp }\end{array}$} \\
\hline & \multicolumn{2}{|c|}{$40 \%$} & \multicolumn{2}{|c|}{$60 \%$} & \multicolumn{2}{|c|}{$40 \%$} & \multicolumn{2}{|c|}{$60 \%$} \\
\hline & MS & FDN & MS & FDN & MS & FDN & MS & FDN \\
\hline & $D M$ & $N D F$ & $D M$ & $N D F$ & $D M$ & $N D F$ & $D M$ & $N D F$ \\
\hline $\mathrm{a}(\%)$ & 34,02 & - & 34,02 & - & 32,20 & - & 32,20 & - \\
\hline $\mathrm{b}(\%)$ & 62,89 & 36,48 & 58,96 & 37,78 & 51,88 & 32,28 & 49,03 & 34,02 \\
\hline DE kp $2 \%$ & 87,18 & 36,48 & 80,30 & 37,78 & 72,91 & 32,28 & 67,90 & 34,02 \\
\hline $\begin{array}{c}E D \operatorname{kp~} 5 \% \\
\text { DP }\end{array}$ & 77,22 & 25,40 & 69,40 & 26,90 & 62,80 & 21,71 & 60,74 & 23,89 \\
\hline$P D$ & 96,52 & 46,23 & 90,33 & 52,60 & 82,47 & 40,61 & 76,62 & 42,58 \\
\hline $\mathrm{kd}(\% / \mathrm{h})$ & $11,11 \mathrm{a}$ & 4,98 & $8,28 \mathrm{~b}$ & 5,58 & $7,22 \mathrm{c}$ & 4,45 & $5,97 \mathrm{c}$ & 5,38 \\
\hline
\end{tabular}

Médias seguidas pelas mesmas letras nas linhas não diferem $(P>0,05)$ pelo teste Tukey. Means followed by the same letter are not different $(P>.05)$ by Tukey test.

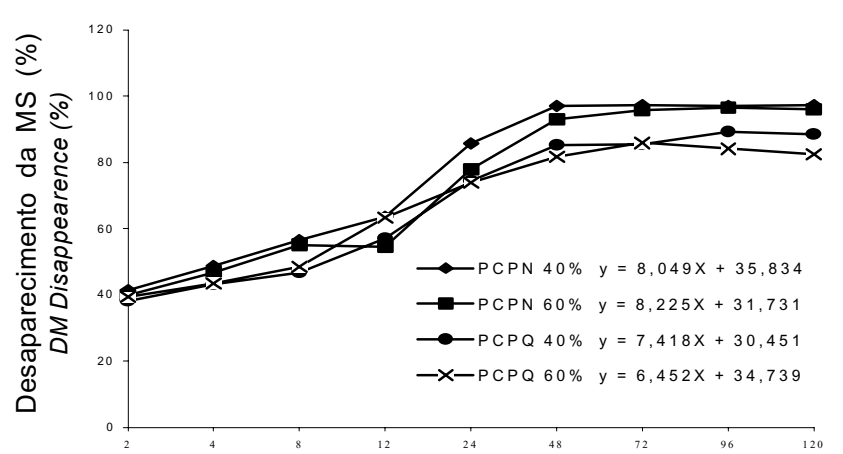

Tempos de incubação (horas) Incubations times (hours)

Figura 1 - Desaparecimento da MS da PCPN e da PCPQ, nos tempos de incubação (\%).

Figure 1 - DM Disappearance of CPPR and CPPB, according to the incubations times (\%).

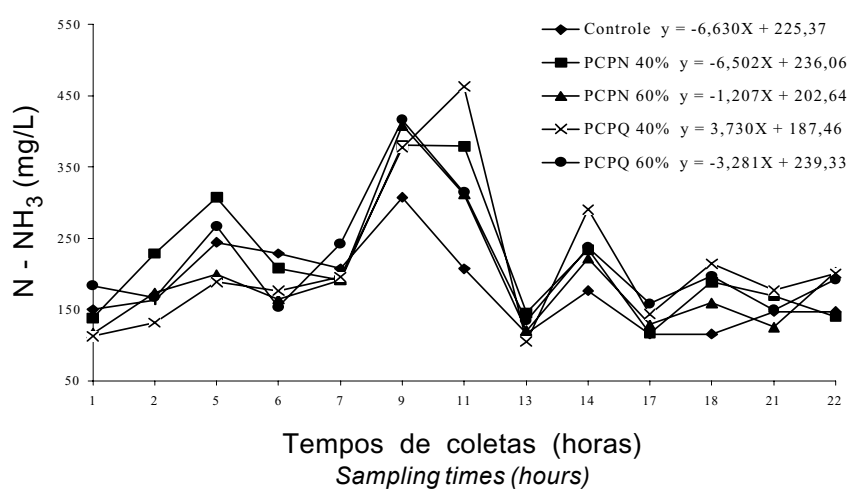

Figura 2 - Concentração de amônia (mg de $\mathrm{NH}_{3} / \mathrm{L}$ ), obtidas durante o período experimental para as diferentes rações contendo PCPN, PCPQ ou controle.

Figure 2 - Ammonia concentration ( $m g \mathrm{NH}_{3} / \mathrm{L}$ ), obtained during the experimental period for the different diets with CPPR, CPPB or control.

R. Bras. Zootec., v.33, n.1, p.258-266, 2004 
para os tratamentos em relação aos tempos de coleta. O horário das 9 horas foi o que apresentou maior pico, devido ao fornecimento de toda a silagem e metade do concentrado, que era feito às 7 horas, seguido do horário das 14 horas, pois recebiam a outra parte do concentrado. Às 5 horas observou-se grande intensidade de ruminação, estando os animais em jejum, com pouco conteúdo ruminal, o que eleva a concentração de amônia. Esses resultados são semelhantes às observações de Owens \& Zinn (1988), que também encontraram picos de amônia uma a duas horas após a alimentação, atribuindo este resultado à solubilidade das fontes protéicas.

Os horários que apresentaram as menores concentrações de $\mathrm{N}-\mathrm{NH}_{3}$ foram os da $1 ; 6 ; 13 ; 17$ e 21 horas, períodos estes em que os animais se encontravam em jejum, antes do fornecimento da alimentação.

\section{Conclusões}

A inclusão de PCP nas rações, independentemente de ser queimada ou não, melhorou a digestibilidade da MS e de seus nutrientes com exceção para $\mathrm{PB}$.

A PCPN apresentou maiores coeficientes de digestibilidade dos nutrientes, quando comparada à PCPQ.

A PCPQ apresentou médias inferiores às da PCPN em relação à degradação da MS e FDN.

Apesar disso, a PCPQ pode ser utilizada na alimentação de bovinos, sendo sua utilização pautada na relação custo benefício.

\section{Literatura Citada}

ABECITRUS. Exportações de farelo de polpa cítrica safra 00/01. (Internet: http: \labecitrus.com.br. 03/09/2002)

AROEIRA, L.J.M.; LOPES, F.C.F.; DAYRELL, M.S. Degradabilidade de alguns alimentos no rúmen de vacas Holandês/Zebu. Revista Brasileira de Zootecnia, v.25, n.6, p.1178-1186, 1996.

BEN-GHEDALIA, D.; YOSEF, E.; MIRON, J. et al. The effects of starch-and pectin- rich diets on quantitative aspects of digestion in sheep. Animal Feed Science and Technology, v.24, n.3-4, p.289-298, 1989.

BHATTACHARYA, A.N.; HARB, M. Dried citrus pulp as grain replacement for awasi lambs. Journal of Animal Science, v.36, n.6, p.1175-1180, 1973.

CARVALHO, M.P. Citros. In: SIMPÓSIO SOBRE NUTRIÇÃO DE BOVINOS, 6., 1995, Piracicaba. Anais... Piracicaba: Fundação de Estudos Agrários Luiz de Queiroz, 1995. p.171-214.

FEGEROS, K.; ZERVAS, G.; STAMOULI, S. et al. Nutritive value of dried citrus pulp and its effect of milk yield and milk composition of lactating ewes. Journal of Dairy Science, v.78, n.4, p.1116-1121, 1995.
GIARDINI, W. Polpa de citrus: o que é? Revista Batavo, v.4, n. 23 p. $1-4,1993$.

HALL, M.B. New equations may improve NSC estimating. Feedstuffs, v.69, n.37, p.12-14, 1997.

HENTGES Jr., J.F.; MORE, J.E.; PALMER, A.Z. et al. Replacement value of dried citrus meal for corn meal in beef cattle diets. Florida: Florida Agricultural Experiment Station Bull, 1966. 708p.

HUNTINGTON, J.A.; GIVENS, D.I. The in situ technique for studying the rumen degradation of feeds: a review of procedure. Nutrition Abstracts and Review (Serie B)., v.65, n.2, p.63-93, 1995.

LANZA, A. Dried citrus pulp in animal feeding. In: DEVOLPMENTS IN FOOD SCIENCE: Food Industries and the Environment, 1984, p.189-198.

MEHREZ, A.Z.; ØRSKOV, E.R. Rates of rumen fermentation in relation to ammonia concentration. The Proceedings of the Nutrition Society, v.35 n.40, p.36-39, 1976.

MEHREZ, A.Z.; ØRSKOV, E.R. A study of the artificial fiber bag technique for determining the digestibility of feeds in the rumen. Journal of Agricultural Science, v.88 n.4, p.645$665,1977$.

NATIONAL RESEARCH COUNCIL - NRC. Nutrient Requirements of dairy cattle. 7.ed. Washington, D.C.: National Academy of Science, 2001. 381p.

PEREIRA, J.R.A.; ROSSI JR., P. Manual prático de avaliação nutricional de alimentos. Piracicaba: undação de Estudos Agrários Luiz de Queiroz, 1994. 34p.

ØRSKOV, E.R.; McDONALD, I. The estimation of protein degradability in the rumen from incubation measurements weighted according to rate of passage. Journal of Agricultural Science, v.92, n.2, p.499-502, 1979.

OWENS, F.N.; ZINN, R. Metabolismo de la proteína en los ruminantes. In: CHURCH, D.C. (Ed.) El ruminante: fisiológia digestiva e nutricíon. Zaragoza: Acribia, 1988. p.255-281.

PRESTON, T.R. Analytical methods for caracterizing feed resources for ruminants. In: CHURCH, D.C. (Ed.) El ruminante: fisológia digestiva e nutricíon. Zaragoza: Acribia, 1988. p.255-281.

STATISTICAL ANALYSES SYSTEM - SAS. SAS user's guide: statistics. 5.ed. Cary: 1990. v.1, 956p.

SATTER, L.D.; ROFFLER, R.E. Nitrogen requirement and utilization in dairy cattle. Journal of Dairy Science, v. 58 , n. 8, p.1212-1237, 1979.

SHULTZ, T.A.; COLLAR, C.A.; BATH, D.L. et al. Rumen digestion of various dairy feedstuffs compared in tests. California Agriculture, v.47, n.3, p.29-32, 1993.

SILVA, D.J. Análise de alimentos: métodos químicos e biológicos. Viçosa, MG: Universidade Federal de Viçosa, 1990. $166 \mathrm{p}$.

STERN, M.D.; ZIEMER, C.J. Consider value, cost when selecting nonforage fiber. Feedstuffs, v.65, n.2. p.14-17, 1993.

Van SOEST, P.J. Nutritional ecology of the ruminant. 2.ed. Cornell: Cornell University Press, 1994. 476p.

WAINMAN, F.W.; DEWEY, J.S. Feedingstuffs evaluation unit - fifth report. Rowett Research Institute, 1988. 123p.

WALLACE, J.R. Ruminal microbial metabolism of peptides and aminoacids. Journal of Nutrition, v.126, n.45, p.1226-1234, 1995. 